\title{
Defining Creativity and the Creative: Searching for the Elusive Creative Personality
}

\author{
Donna L. Roberts, PhD \\ Embry-Riddle Aeronautical University
}

\begin{abstract}
This research consists of a qualitative analysis examining the various definitions, both theoretical and practical, of creativity, the creative process and the creative personality. The phenomena of creativity and creative problem solving, and their ever-evolving characterizations, is researched across time and culture. From the dialogues of Socrates, who equated creativity with the divine intervention of the Muses, to the mathematical formula of Ruth Noller, an operational definition of what it means to be creative is explored. As such, this research attempts to develop a comprehensive picture of the creative personality, then and now, considering cultural, temporal and technological contexts. Creativity, as it encompasses the concept of originality and is manifested in such behaviors as the generation of uniquely novel, uncommon ideas and solutions, is analyzed to operationalize these conceptual domains. Scientific and scholarly research on creativity in both the arts and the sciences, is analyzed for convergent and divergent themes. Additionally, biographies of famous creatives are assessed in relation to their conformity (or nonconformity) to the creative personality. Componential theory, which encompasses the social and psychological components necessary to produce creative work, serves as a framework to engage in the comprehensive analysis of the creative process as it evolves within the context of its environment. From the perspective of creativity as a general, overarching capacity, to its antithesis as skill and genius in a single domain, creativity and the creative is examined with respect to both intellect and its practical application.
\end{abstract}

Keywords: creative personality; creativity; genius; personality; problem solving; 